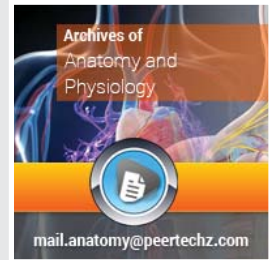

Clinical Group

\title{
Archives of Anatomy and Physiology
}

\section{Stancho Stanchev*, Alexandar Iliev, Georgi Kotov, Lina Malinova and Boycho Landzhov}

Department of Anatomy, Histology and Embryology, Medical University of Sofia, Bulgaria

Received: 16 January, 2018

Accepted: 23 January, 2018

Published: 24 January, 2018

*Corresponding author: Stancho Stanchev, MD, Department of Anatomy, Histology and Embryology Medical University of Sofia, Bulgaria, Tel: +35929172609; E-mail: stanchev_1989@abv.bg

Keywords: Glomerulosclerosis, Renal corpuscles, Morphometry,Hypertension,Spontaneouslyhypertensive rat (SHR)

https://www.peertechz.com
Research Article

\section{A comparative morphometric study} of the superficial and juxtamedullary nephrons during the postnatal development in spontaneously hypertensive rats

Background: Hypertensive nephrosclerosis is associated with progressive loss of functional nephrons leading to chronic renal failure. In our study, we analysed the changes in the areas of the renal corpuscles and glomerular capillary tufts of superficial and juxtamedullary nephrons in 9 male spontaneously hypertensive rats, distributed in the following age groups: 4, 6 and 12-month-old.

Results: The initial increase in the areas of the renal corpuscles and glomeruli representing the compensatory glomerular hypertrophy was followed by decrease in the late stages of glomerulosclerosis. Our results show that juxtamedullary nephrons were more affected than superficial nephrons.

Conclusion: Hypertensive nephrosclerosis is associated with both morphological and morphometric changes in nephrons, which lead to declining renal function.

\section{Introduction}

The prolonged and untreated hypertension is an important risk factor for the development of inevitable structural alterations in many organs and systems, which are collectively described by the term "target organ damage" [1]. In addition, the relationship between elevated blood pressure and chronic renal failure is pathologically referred to as hypertensive nephrosclerosis [2]. It is characterized by progressive morphological parenchymal and interstitial changes - hyaline and fibrinoid arteriosclerosis, intimal smooth muscle cell proliferation of the interlobular and small arteries, and duplication of the internal elastic lamina of arcuate arteries, interstitial fibrosis, tubular atrophy and glomerulosclerosis [3]. In the literature, two types of glomerular injury have been described - solidification and obsolescence. The obsolescent form is characterized by collapse of the glomerulus and intracapsular fibrosis, while the solidification is represented by expansion of mesangeal matrix and enlargement of the glomerular tuft [4].

The spontaneously hypertensive rat (SHR) strain was first derived by Okamoto and colleagues during the 1960s and is the most commonly used experimental model of human essential hypertension [5]. The elevation of blood pressure in SHR begins at 4 weeks of age and the renal morphological changes can be observed at 6-12 months of age. In addition, the severity of the glomerular lesions and tubulointerstitial changes under hypertonic conditions appears to be more pronounced in the inner rather than the outer cortex [6].

The aim of the present study was to analyze and compare the areas of the renal corpuscles and glomerular capillary tufts of the superficial and juxtamedullary nephrons traced among three age groups (4-month-old, 6-month-old and 12-monthold) male SHR.

\section{Materials and Methods}

In the present study, we used histological material from the kidneys of male SHR. The total number of SHR was 9, distributed in three age groups, each containing three animals: four months old; six months old and twelve months old. All experiments were conducted with the approval of the University Committee on Animal Resources (№ 4866). All animals received humane care in compliance with the "Principles of laboratory animal care" formulated by the National Society for Medical Research and the "Guide for the care and use of laboratory animals" prepared by the National Institute of 
Health (NIH publication No. 86-23, revised 1996). The rats were anaesthetised intraperitoneally with Thiopental $40 \mathrm{mg} /$ $\mathrm{kg}$ b.w. The chest cavity was opened and transcardial perfusion was made with $4 \%$ paraformaldehyde in $0.1 \mathrm{M}$ phosphate buffer, $\mathrm{pH}$ 7.2. Kidneys were quickly removed and fixed in $10 \%$ neutral-buffered formalin. After routine embedding, serial coronal $5 \mu \mathrm{m}$ thick sections were cut and stained routinely with haematoxylin and eosin. Haematoxylin and eosin staining was conducted in the following way: after removal of the paraffin with xylol, we washed the slides with water and stained them with haematoxylin for 5 minutes. They were then stained with an eosin solution for 10 minutes, washed again with water and embedded in entellan.

The morphometric analysis was performed on five slides from the kidney of each animal. Quantitative data were obtained with a computerised system for image analysis NISElements Advanced Research (Ver. 2.30). The areas of interest in each slide were first found on low magnifications (x100, x200), taking into account the respective age group. Results were obtained through assessment of randomly selected zones of the renal cortex with no significant ruptures resulting from the processing technique of the histological material that could compromise the proper data analysis. The standardization of the zone where the areas of renal corpuscles and glomeruli were measured was performed in line with the following criteria in order to certify the authenticity of the results: 1 . only renal corpuscles with clearly demarcated vascular and tubular poles were included in this study; 2 . the selected renal corpuscles of the superficial nephrons were situated in the periphery of the cortex; 3 . the analyzed renal corpuscles of the juxtamedullary nephrons were located adjacent to the medulla. The following morphometric parameters of the superficial and juxtamedullary nephrons during the postnatal development of SHR were analyzed: area of the renal corpuscles of the superficial nephrons $\left(\mu \mathrm{m}^{2}\right)$, glomerular area of the superficial nephrons $\left(\mu \mathrm{m}^{2}\right)$, area of the renal corpuscles of the juxtamedullary nephrons $\left(\mu \mathrm{m}^{2}\right)$, glomerular area of the juxtamedulllary nephrons $\left(\mu \mathrm{m}^{2}\right)$. The obtained quantitative data were demonstrated with Bar Chart/ Bar Plot diagrams and were statistically evaluated through a Student-T-test. Statistically significant differences were read in the case of $\mathrm{p}<0.05$. Microsoft Office Excel 2010 was used to process the data and to demonstrate the obtained results in an adequate way.

\section{Results}

Results were obtained through assessment of randomly selected areas of the kidneys of SHR, aged 4-, 6- and 12-monthold, which were stained with haematoxylin and eosin. The selected areas included either superficial (Figures 1-3) or juxtamedullary nephrons (Figures 4-6). The results were organized in the form of tables and diagrams, representative of the obtained quantitative data for the studied morphometric parameters.

In the group of 4-month-old animals, the comparative analysis of the parameter area of the renal corpuscles shows higher values in juxtamedullary nephrons as opposed to superficial nephrons. That trend was preserved in the group of 6-month-old SHR, where we noted that the increase of the area of the renal corpuscles of juxtamedullary nephrons was more pronounced than the respective increase in superficial nephrons; furthermore, it reached its highest value in this group. In the group of 12-month-old SHR, the area of the renal corpuscles in superficial nephrons increased compared to the value in 6-month-old SHR, while in juxtamedullary nephrons, we reported a decrease in the area of the renal corpuscles, which was comparable to the obtained results in 4-monthold animals (Figure 7) (Table 1). In all age groups, the value of the parameter remained higher in juxtamedular nephrons, however in the group of 12-month-old SHR, the values were closer and this difference was less pronounced.
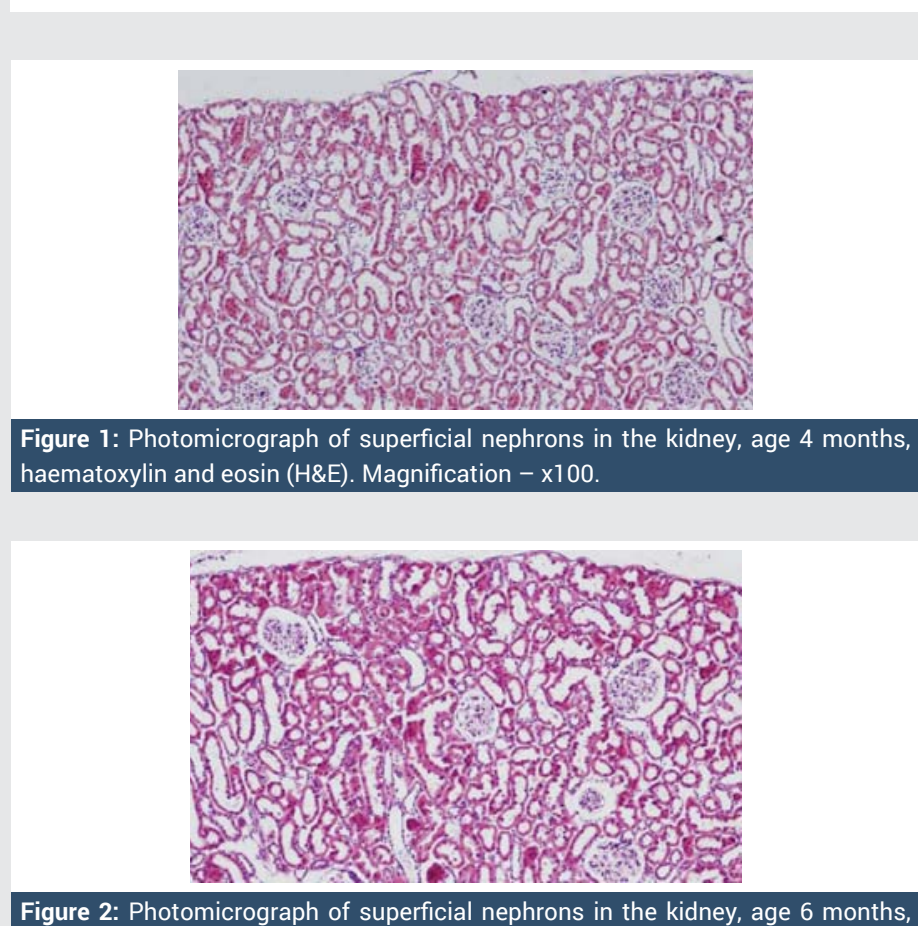
haematoxylin and eosin (H\&E). Magnification - x100.

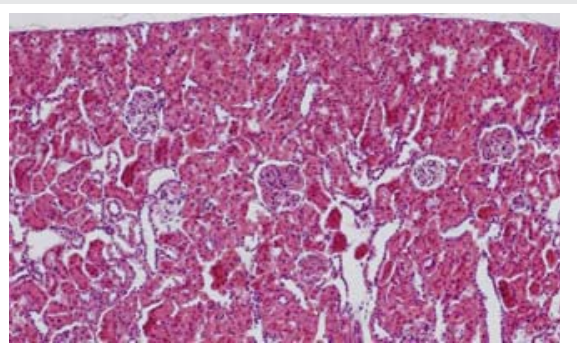

Figure 3: Photomicrograph of superficial nephrons in the kidney, age 12 months, haematoxylin and eosin (H\&E). Magnification - x100.

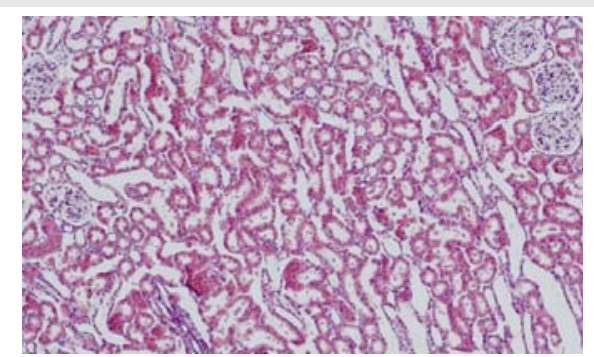

Figure 4: Photomicrograph of juxtamedullary nephrons in the kidney, age 4 months, haematoxylin and eosin (H\&E). Magnification - x100. 


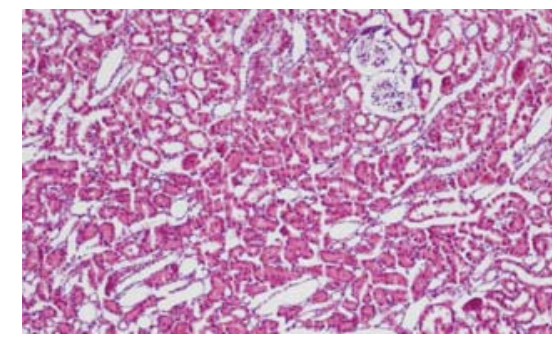

Figure 5: Photomicrograph of juxtamedullary nephrons in the kidney, age 6 months, haematoxylin and eosin (H\&E). Magnification - x100.

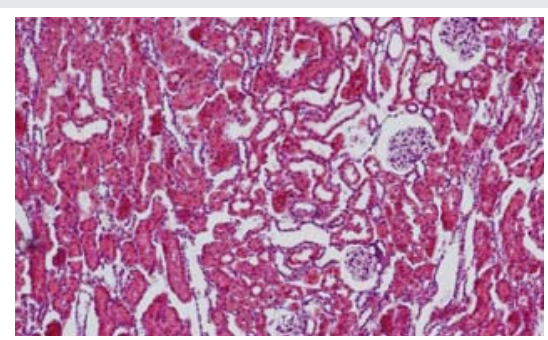

Figure 6: Photomicrograph of juxtamedullary nephrons in the kidney, age 12 months, haematoxylin and eosin (H\&E). Magnification - x100.

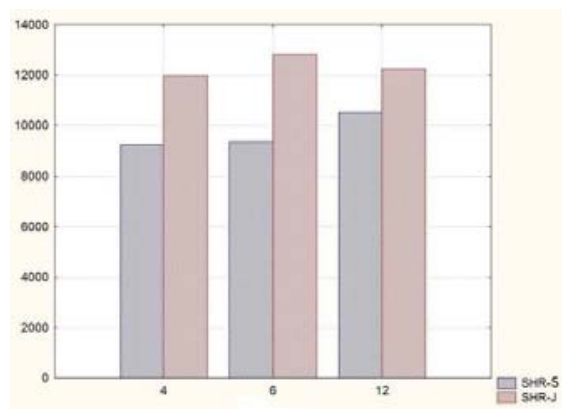

Figure 7: Graphical representation of the comparative analysis of the morphometric parameter area of renal corpuscles of superficial (SHR-S) and juxtamedullary nephrons (SHR-J) in spontaneously hypertensive rats. X-axis: age-groups of SHR. Y-axis: area of renal corpuscles $(\mu \mathrm{m} 2)$.

Table 1: Numerical representation of the comparative analysis of the morphometric parameter area of renal corpuscles in spontaneously hypertensive rats.

\begin{tabular}{|c|c|c|c|c|c|}
\hline \multirow{3}{*}{$\begin{array}{l}\text { SHR } \\
\text { Age }\end{array}$} & \multirow{2}{*}{\multicolumn{2}{|c|}{$\begin{array}{c}\text { Superficial nephrons } \\
\text { Area of renal corpuscles }\end{array}$}} & \multirow{2}{*}{\multicolumn{2}{|c|}{$\begin{array}{l}\text { Juxtamedullary nephrons } \\
\text { Area of renal corpuscles }\end{array}$}} & \multirow{3}{*}{ TTEST } \\
\hline & & & & & \\
\hline & $\begin{array}{c}\text { Mean value } \\
-\mu m^{2}\end{array}$ & SD & $\begin{array}{l}\text { Mean value - } \\
\qquad \mathrm{m}^{2}\end{array}$ & SD & \\
\hline 4 months & 9238.8 & 861.2 & 11975.1 & 921.9 & $\begin{array}{c}\mathrm{p}< \\
0.00001\end{array}$ \\
\hline 6 months & 9359 & 713.2 & 12834.3 & 1020 & $\begin{array}{c}p< \\
0.000001\end{array}$ \\
\hline $\begin{array}{c}12 \\
\text { months }\end{array}$ & 10504.2 & 1265.8 & 12245.6 & 762.4 & $\begin{array}{c}p< \\
0.000001\end{array}$ \\
\hline
\end{tabular}

The comparative analysis of the glomerular area of superficial and juxtamedullary nephrons in the group of 4-month-old SHR showed a greater value of the parameter in juxtamedullary nephrons. As aging advanced, in 6-monthold animals, we reported an increase in the parameter in both types of nephrons; however, in juxtamedullary nephrons this change was much more pronounced and constituted an increase of more than $40 \%$, while in superficial nephrons the increase was approximately $20 \%$. In the group of senescent SHR (12-month-old) a decrease in the glomerular area was observed both in superficial and juxtamedullary nephrons (Figure 8) (Table 2). However, this decrease was better pronounced in juxtamedullary nephrons, where the value of the parameter decreased with more than $25 \%$, while in superficial nephrons, the decrease in the value was approximately $10 \%$.

\section{Discussion}

In the present study, we conducted a detailed comparative morphometric analysis of the changes in the areas of the renal corpuscles and glomerular capillary tufts of the superficial and juxtamedullary nephrons in SHR. More striking changes in the evaluated parameters were observed in juxtamedullary nephrons, while in superficial nephrons the changes were more subtle. Between the groups of 4-month-old and 6-month-old SHR, the values increased for both parameters in both types of nephrons. Comparing 6-month-old with 12-month-old SHR, we noted that the parameter glomerular area decreased in both types of nephrons, while the area of the renal corpuscles decreased in juxtamedullary nephrons but increased in superficial nephrons.

There is evidence that various diseases may affect the morphometric parameters of the renal corpuscles such as glomerular capillary tuft's diameter and Bowman's capsule dimension [7]. Glomerulosclerosis can be observed under pathological conditions such as hypertension, as well as during the process of physiological aging. Smith et al. suggest a formula for estimation of the percentage of age-related sclerotic glomeruli in the human population: age/2-10, when the age is above 40 years [8]. Furthermore, the changes in glomerular size correspond to the phase of glomerulosclerosis - the initial process of glomerular hypertrophy is followed by shrinking of glomerular capillary tufts to a smaller size.

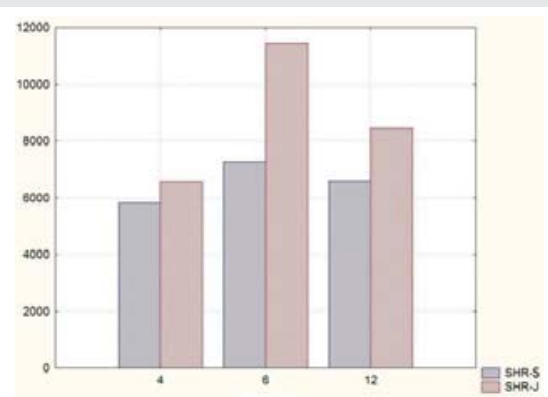

Figure 8: Graphical representation of the comparative analysis of the morphometric parameter glomerular area of superficial (SHR-S) and juxtamedullary nephrons (SHR-J) in spontaneously hypertensive rats. X-axis: age-groups of SHR. Y-axis: glomerular area $(\mu \mathrm{m} 2)$.

Table 2: Numerical representation of the comparative analysis of the morphometric parameter glomerular area in spontaneously hypertensive rats.

\begin{tabular}{|c|c|c|c|c|c|}
\hline \multirow{3}{*}{$\begin{array}{l}\text { SHR } \\
\text { Age }\end{array}$} & \multirow{2}{*}{\multicolumn{2}{|c|}{$\begin{array}{c}\text { Superficial nephrons } \\
\text { Glomerular area }\end{array}$}} & \multirow{2}{*}{\multicolumn{2}{|c|}{$\begin{array}{c}\text { Juxtamedullary nephrons } \\
\text { Glomerular area }\end{array}$}} & \multirow{3}{*}{ TTEST } \\
\hline & & & & & \\
\hline & $\begin{array}{c}\text { Mean value } \\
-\mu \mathrm{m}^{2}\end{array}$ & SD & Mean value $-\mu m^{2}$ & SD & \\
\hline 4 months & 5822.6 & 1013.9 & 6579.4 & 759.8 & $p<0.00001$ \\
\hline 6 months & 7278.5 & 588 & 11446.4 & 1152.9 & $\begin{array}{c}p< \\
0.0000001\end{array}$ \\
\hline \multirow[t]{2}{*}{$\begin{array}{c}12 \\
\text { months }\end{array}$} & 6595.8 & 742.5 & 8453.6 & 517.3 & $\begin{array}{c}p< \\
0.000001\end{array}$ \\
\hline & & & & & 003 \\
\hline
\end{tabular}


However, some authors hypothesise that the functional renal capacity can't be evaluated by the changes in glomerular size and number, because these morphometric parameters depend on the body size and some sclerotic glomeruli can disappear as age advances [9]. Stojanovi'c et al. suggest that glomerular hypertrophy among nonsclerosed glomeruli may be estimated by their connective tissue content [9]. Our study aimed at tracing the changes in two morphometric parameters - area of the renal corpuscles and glomerular area of the superficial and juxtamedullary nephrons. Our findings demonstrate that initially, under hypertensive conditions, there is an increase in the two parameters in both types of nephrons. On the contrary, in the case of advanced hypertension in 12-month-old SHR, the glomerular area decreases markedly in juxtamedullary nephrons and less in superficial nephrons, while the area of the renal corpuscles decreases in juxtamedullary nephrons and increases in superficial nephrons. These findings were interpreted as signs of glomerulosclerosis, which was more pronounced in juxtamedullary nephrons. They experience higher intraglomerular pressure in hypertensive conditions due to the specific blood supply of the kidney (lower pressure and a smaller degree of blood supply in the periphery of the cortex).

Alterations in kidney morphology may lead to development of renal insufficiency and eventually may progress to endstage renal disease (ESRD). ESRD due to hypertension has been reported as the cause of $25 \%$ of newly diagnosed ESRD patients every year in the United States [10]. Most often, hypertensive glomerulosclerosis is observed in the African American population due to a higher severity of elevated blood pressure and poorer socioeconomic status [11]. One study in African American populations found that renal biopsies performed in patients with hypertension more often show presence of focal global glomerulosclerosis (FGGS) rather than focal segmental gloemrulosclerosis (FSGS) [12,13]. Segmental glomerulosclerosis correlated with arteriolar and arterial sclerosis, as well as development of interstitial fibrosis and reciprocal of creatinine levels in the blood serum. Global glomerulosclerosis, on the other hand, has been reported to involve $43+/-26 \%$ of glomeruli $[12,13]$. This type of glomerulosclerosis did not correlate with arteriolar or arterial thickening; however, correlations were established with levels of creatinine and cholesterol in the serum, development of interstitial fibrosis and systolic blood pressure.

\section{Conclusion}

Changes in the morphometric parameters area of the renal corpuscles and glomerular area in superficial and juxtamedullary nephrons correspond to development of hypertensive glomerulosclerosis with advancing age in SHR. These changes are more pronounced in the inner rather than the outer renal cortex. Hypertensive nephrosclerosis is a leading factor in the onset of declining renal function.

\section{References}

1. Nadar SK, Tayebjee MH, Messerli F, Lip GY (2006) Target organ damage in hypertension: pathophysiology and implications for drug therapy. Curr Pharm Des 12: 1581-1592. Link: https://goo.gl/LsqTDE

2. Hill GS (2008) Hypertensive nephrosclerosis. Curr Opin Nephrol Hypertens 17 266-270. Link: https://goo.gl/QhLcya

3. Goldblatt PJ, Gohara AF, Kahn NH, Hampton JA (1989) Benign andmalignant nephrosclerosis and renovascular hypertension, in Renal Patholo with Clinical and Functional Correlations. Philadelphia, Lippincott. Link: https://goo.gl/GrWMgK

4. Hughson MD, Puelles VG, Hoy WE, Douglas-Denton RN, Mott SA, et al. (2014) Hypertension, glomerular hypertrophy and nephrosclerosis: the effect of race. Nephrol Dial Transplant 29: 1399-1409. Link: https://goo.gl/AbXBWv

5. Okamoto K, Aoki K (1963) Development of a strain of spontaneously hypertensive rats. Jap Circ J 27: 282-293. Link: https://goo.gl/5W2eVU

6. Feld LG, Van Liew JB, Galaske RG, Boylan JW (1977) Selectivity of renal injury and proteinuria in the spontaneously hypertensive rat. Kidney Int 12: 332-343. Link: https://goo.gl/wnivU1

7. Kotyk T, Dey N, Ashour AS, Balas-Timar D, Chakraborty S, et al. (2016) Measurement of glomerulus diameter and Bowman's space width of renal albino rats. Comput Methods Programs Biomed 126: 143-153. Link: https://goo.gl/PGciB1

8. Smith SM, Hoy WE, Cobb L (1989) Low incidence of glomerulosclerosis in normal kidneys. Arch Pathol Lab Med 113: 1253-1255. Link: https://goo.gl/ yLGgXW

9. Stojanovi VR, Jovanovi ID, Ugrenovi SZ, Vasovi LP, Živkovi VS, et al. (2012) Morphometric analysis of nonsclerosed Glomeruli size and connective tissue content during the aging process. Sci World J 2012: 845046-845048. Link: https://goo.gl/RdVWX5

10. Schlessinger SD, Tankersley MR, Curtis JJ (1994) Clinical documentation of end stage renal disease due to hypertension. Am J Kidney Dis 23: 655-660. Link: https://goo.gl/SBwKLC

11. Murea M, Freedman BI (2010) Essential hypertension and risk of nephropathy: a reappraisal. Curr Opin Nephrol Hypertens 19: 235-241. Link: https://goo.gl/aG959n

12. Fogo A, Breyer JA, Smith MC, Cleveland WH, Agodoa L, et al. (1997) Accuracy of the diagnosis of hypertensive nephrosclerosis in African Americans: a report from the African American Study of Kidney Disease (AASK) Trial. AASK Pilot Study Investigators. Kidney Int 51:244-252. Link: https://goo.gl/eZgJWp

13. Sethi S, Zand L, Nasr SH, Glassock RJ, Fervenza FC (2014) Focal and segmental glomerulosclerosis: clinical and kidney biopsy correlations. Clin Kidney J 7: 531-537. Link: https://goo.gl/vythoy 